\title{
Netnografik Analizle Türkiye'de YouTuberlar ve Değişen Ahlaki Panik Fenomeni
}

\author{
Işıl Tombul (Dr.) \\ isiltombulizmir@gmail.com
}

\author{
Başvuru Tarihi: 21.11.2019 \\ Yayına Kabul Tarihi: 02.05.2020 \\ Yayınlanma Tarihi: 24.07.2020 \\ https://doi.org/10.17680/erciyesiletisim.649357
}

\section{Öz}

Her yeni teknolojik değişim ve bu değişimin getirdiği yeni kültür desenlerinin eski kültürel yapılarla çatışmasından dolayı sosyal medya üzerine yapılan tartışmalar, yeni bir konu değildir; neredeyse teknolojinin hayatımıza girdiği dönemden beri vardır. Web 2.0 teknolojisinin gelişip hizmet alanını artırmasıyla insanların daha ă̆ tabanlı (networked) bir gündelik hayatı içinde, kamu ve özel alan ister istemez giriftleşmekte, yeni teknolojiler eski bağlamsal yapıları ve mekânları çökertmektedir. Bu sanal mekânda karşımıza çıkan mikro-ünlülük fenomeni; insanların semantik alanda yerleştiremedikleri yeni tekno-bağlamsızlık sebebiyle dönem dönem paniğe neden olmaktadır. Teknolojiyle ilgili ve bilhassa sosyal medya fenomenleri üzerine yapılan panik tartışmaları, genellikle ahlaki değerler üzerinden dönmektedir. Modernitenin ya da Batı yürüyüşünün bizzat Batı'da durmaya başladığı andan itibaren tartışılan ahlaki panik kavramı, özellikle Batı toplumları bașta olmak üzere 1960'lardan bugüne toplumlarda bazı dönemlerde görülmeye başlanmıştır. Geç modernitenin sorgulandığı, postmodernitenin tartışıldığı ve eko-sosyo-politik tartışmaların bolca yaşandığı bir zaman diliminde bu kavram, dönemin sosyologları Jock Young tarafindan 1971'de kullanılmış, Stanley Cohen tarafından 1972'de kuramlaştırılmış, 1975'te Stuart Hall ve Tony Jefferson, 1979'da Dick Hebdige tarafından altkültür araştırmalarında benimsenmiștir. Bu çalışmada ahlaki panik konusu, Türkiye'deki YouTuber fenomenleri üzerinden ele alınmaktadır. Çalışmanın amacı Ekim - Kasım 2018 tarihlerinde, Türk medyasında YouTuberlar hakkında çıkan ahlaki paniğin çevrimiçi alandaki yansımalarını ortaya koymaktır. Çevrimiçi kültürün gerçek hayattaki normsal pratiklerden farkı yoktur. Sanal alanda belli fenomenler, ünlüler, kanallar, konular üzerinden oluşan topluluk kültürü vardır. Bu kültürel yapı gerçek dünyadan bağımsız değildir. Dışarıda konuşulan paniğin içerideki yansımaları bize paniğin boyutunu göstermesi açısından önemlidir. Kültürel çalışmalar ve antropolojik yaklaşımlar bu konuda en çok tercih edilen yöntemlerdir. Konunun dijital alanda kendine ait bir gerçekliğe sahip olmasından dolayı, dijital etnografik bir yaklaşım sunan netnografik yöntem kullanılmıştır. Çünkü çevrimiçi topluluğun hayranlar (fan) ve sevmeyenlerin (hater) birlikte olușturduğu bir kültürel alanı vardır. Gerçek hayatta yapılan ahlaki tartışmaların sanal alana yansımaları ve bu paniğin nasıl algılandığı çevrimiçi toplulukta verilen tepkiler üzerinden analiz edilmeye çalışılmıştır.

Anahtar Kelimeler: Ahlaki Panik, YouTuber, Mikro-Ünlülük, Çevrimiçi Kültür, Netnografi. 


\title{
YouTubers and Changing Moral Panic Phenomenon In Turkey with Netnographic Analysis
}

\author{
Işıl Tombul (Ph.D.)
}

isiltombulizmir@gmail.com

Date Received: 21.11.2019

Date Accepted: 02.05.2020

Date Published: 24.07.2020

https://doi.org/10.17680/erciyesiletisim.649357

\begin{abstract}
The debates on social media is not a new matter because every new technological change and the new cultural patterns could lead to clashes with old cultural structures. This continues to exist since technology entered our lives. With the development of Web 2.0 technology and its widespread use, the public and private spaces inevitably become intricate in a more networked daily life of people; and new technologies break down the old contextual structures and spaces. The phenomenon of micro-celebrity in this virtual space causes panic from time to time due to the new techno-contextlessness that people cannot place in the semantic field. Debates on panic by means technology and especially with social media often revolve around moral values. In a period in which late modernity was questioned, postmodernity was discussed, and eco-socio-political debates were abundant, this concept was used by Jock Young in 1971, theorized by Stanley Cohen in 1972 and adopted in subculture researches by Stuart Hall and Tony Jefferson in 1975 and Dick Hebdige in 1979. In this study, these concepts are discussed through YouTube influencers in Turkey. The study aims to reveal the reflections of the moral panic on YouTubers in the Turkish media in October - November 2018 in the online field. Online culture is no different from normative practices in real life. In the virtual space, there is a community culture around certain phenomena, celebrities, channels, topics. This cultural structure is not independent from the real life. The internal reflections of the panic spoken outside are essential in that they exhibit the extent of panic. Cultural studies and anthropological approaches are the most preferred methods. In this study, the netnographic analysis method, which presents a digital ethnographic approach, has been used, since the subject has its reality in the digital field, because the online community has cultural space where fans and haters are together. Reflections of real-life moral debates on the virtual space and how this panic is perceived are analyzed through the responses of the online community.
\end{abstract}

Keywords: Moral Panic, YouTuber, Micro-Celebrity, Online Culture, Netnography. 


\section{Giriş}

Ahlaki panik; önce Jock Young (1971) tarafından The Role of the Police as Amplifiers of Deviancy, Negotiators of Reality and Translators adlı makalesinde kullanılmış; İngiliz toplumunda gençler arasında uyuşturucu kullanımı ve medyanın konuyu abartarak nasıl panik yarattığı ele alınmıștır. Öyle ki uyuşturucu kullanımına dair ahlaki panik, polis departmanında uyuşturucu ekiplerinin kurulmasına ve tutuklamaların artmasına neden olmuştur. Daha sonra Young'ın çalışmalarını referans gösteren Stanley Cohen'ın (2002) kitabı Folk Devils and Moral Panics: The Creation of the Mods and Rockers ise 1972'de yayınlanmıștır. Kitapta 1964'te yaşanan İngiltere'deki müzik altkültürleri olan Mods Rockers ile ilgili olaylar incelenmiştir. Bu kitap, Cohen'ın 1967-69'da yazılmış doktora tezine dayanmakta; suçluluk, gençlik kültürleri, alt kültürler, stil, vandalizm, uyuşturucu ve futbol holiganlığı gibi yeni sapma sosyolojisi ve embriyonik kültürel çalışmalar tarafından paylaşılan konularda rezonansa girilmektedir.

Aynı dönemde Birmingham Çağdaş Kültürel Çalışmalar Merkezinde yürütülen gençlik ve altkültürler üzerine öncü çalışmalar yapan S. Hall ve ekolü Young ve Cohen'ın tezlerinden yola çıkarak yeni araştırmalar yapmıștır. Stuart Hall ve Tony Jefferson Resistance Through Rituals: Youth Subcultures in Post-War Britain (1975) ve Dick Hebdige Subculture: The Meaning of Style (1979) eserleriyle gençlik kültürünü analiz etmiștir. Örneğin Hall, Critcher, Jefferson, Clarke ve Roberts (1978, s. vii-17), 1972-1973'te "soygun" hakkında İngiliz toplumunda ahlaki bir panik olduğunu iddia ederken bu paniğin Cohen'ın ahlaki panik fenomeni ile ilgili açıklanan sürecin benzeri olarak neredeyse her ayrıntısına sahip olduğunu belirtirler. Hall ve diğerleri, bir sokak suçundan ziyade sosyal bir fenomen olarak "soygun" ile ilgilendiklerini belirttikleri çalışmalarında, sorunun sosyal sebeplerinin ne olduğunu tartışmışlardır. Soygunların aniden İngiliz sokaklarında göründüğü doğruysa toplumun soygun hakkında ahlaki bir paniğe girdiği de bir gerçektir ve bu durum, 1960'larda ortaya çıkan, sürekli artan, şiddet içeren suç oranı hakkındaki panik ile ilgilidir.

1960’larda İngiliz işçi sınıfına mensup gençlerin kültürü üzerine yapılan çalışmalar ve bu altkültürlerin toplumda şiddet başta olmak üzere birçok sorun yarattığına dair oluş(turul)an algının denk geldiği geç modernite dönemi elbette tesadüf değildir. Modernizmin hiç bitmeyecekmiş gibi görünen pürüzsüz yürüyüșünün durmaya başladığı savaş sonrası Avrupa kültürü içinde, sistemik sorunların ilk patlak verdiği yer, altkültürler olmuştur. Çünkü altkültürlerin, Phil Cohen'ın (1972, s.23) deyişiyle, ana kültürde gizlenmiş veya çözülmemiş çelişkileri ifade etmek ve çözmek gibi gizli bir işlevi vardır. Bu nedenle konvansiyonel savaşın hâlâ süren yorgunluğu, Soğuk Savaş'ın kutupsallığı, petrol krizleri, ekonomik krizler, Batı dışındaki ülkelerde modernist emplantasyonun tutmayışı, üniter ve parlamenter sistemlerin sorgulanması, modern paradigmanın bizzat doğduğu yerlerde eleştirilmesi, bağımsızlık mücadeleleri, öğrenci olayları ve daha birçok konu dönemin ekonomik, sosyal ve politik atmosferini etkilerken artık modern sonrası bir sürecin başladığını da netleştirmekteydi. Yeni gelen postmodern dönemde çoğulculuk, belirsizlik, bireysellik, kimlik vb. konular ön plana çıkarken bu dönemde ilk adımlarını atmaya başlayan bilgisayar teknolojisi ise âdeta modernizm sonrası boşluğu topluluk ya da bireysel bazda kimliksel fenomenlerle yeni medya ile doldurmaya gelmişti. Ancak yeni medya, modernitenin tekrarlayan bir içsel döngüsü (Drotner, 1999, s.18) ile ahlaki kaygıları da beraberinde getirmiştir.

İletişim teknolojilerindeki gelişmelerin kültürel alana yansımaları, hem modernist hem de postmodernist dönemden farklı bir süreci beraberinde getirmiştir. Küresel-yerel, 
kamusal-özel, erkek-kadın gibi birçok konuda ele alabileceğimiz modernist dualist kavramların yerle bir olduğu ve bağlamların çöktügü bir semantik içinde, dijitalizmle büyümeyen kuşaklarda yeni yașam pratikleri bir paniği de beraberinde getirmiştir. $\mathrm{Bu}$ nedenle internetin sosyal hayatımıza girdiği andan itibaren yapılan tartışmaların merkezini ahlak ve değerler oluşturmaktadır. Çünkü kuşaklar arasındaki süreklilik, yeni teknolojiler ile kesintiye uğrayabilmekte ya da öyle olduğu düşünülebilmektedir. Çok eleştirilen konular, özellikle Web 2.0 teknolojisinin getirdiği içerik üretiminden sonra karşımıza çıkmıştır. Çünkü yeni medyanın içerik üretmeyi ve paylaşmayı sağlayan ortamı, sadece bir medya hizmeti değildir; yazılı ya da görsel metinsel tabanlı eylemde bulunan öznenin (kullanıcının), belirli bir kitle karşısında benlik sunumu yaptığl, bu kitle ile etkileşimli bir çevrimiçi kültüre sahip olduğu tekno-sosyal derin bir yapıya gömülüdür. Buradaki bütün dünya -kimliklerimiz, benliklerimiz, bedenlerimiz vb. her şey- metinseldir. Bu metinsellik, dilsel ve fenomenolojik bir anlamı birlikte üretir. Şöhret fenomeni iște tam da bu anlam üretimi içinde karşımıza çıkar.

Mikro-ünlü denilen sosyal medya fenomenleri özellikle 2010'dan sonraki süreçte, önce Instagram ve YouTube platformları üzerinden karşımıza çıkmıștır. Burada ünlü olan isimlerin milyonlarca takipçisi olabilmektedir. YouTuber kendisiyle ilgili ya da ele aldığı konular üzerinden sosyal medyada bir içerik üretmekte ve bu içerik üretimi etrafında toplanan bir hayran kitlesi olmaktadır. Bu kitle (hayran/fan ve sevmeyen/hater), aynı zamanda içerik ve içerik üreticisi etrafında oluşan çevrimiçi topluluğu da meydana getirmektedir. Bu çevrimiçi topluluk ile içeriği paylaşan arasında etkileşimli bir iletişim vardır. Topluluk içerik üreticisinden bazı taleplerde bulunabilir, içerik üreticisini eleștirebilir ve böylece onu nasıl algıladığını yorumlarıyla gösterebilir. Bir anlamda, bu çevrimiçi topluluğun oluşturduğu kültür, bize etnografik bir veri sunar. Sosyal medyanın kamusal ve özel alanı birlikte içermesinden dolayı, bu yorumlar kültürde önemli değişimlerin olduğunu görmemiz açısından bir vaka analizi olarak karşımıza çıkmaktadır. Özellikle son dönemde, dünyada YouTuberlar ile ilgili çok tartışmalı içerik üretimleri görüldüğü gibi benzer tartışmalar Türkiye'deki YouTuberlar üzerinden de yapılmaktadır. Aslında tartışmalar sosyal medya fenomenlerinin çıkmasından beri hep vardı; ancak medyanın konuya dâhil olmasıyla daha geniş bir ahlaki panik yaşanmıştır. Türk YouTuberların kamuoyunda en çok tartışıldığı dönem ise 2018 yılının ekim ayında başlamış ve takip eden aylarda devam etmiştir.

YouTuberlarla ilgili uzun zamandır tartışmalar olsa da ahlak paniğinin net olarak gözlemlendiği tartışmalar, 20 Ekim 2018'de Enes Batur'un YouTuber jargonunda "kışkırtma videosu" denilen paylaşımının küfür içermesiyle başlamıștır. Batur, aynı yıl Altın Kelebek Ödül Töreni'nde ödüller arasına ilk kez verilen 'En İyi YouTuber Ödülü'nü kazanmıştır (İnternet Haber, 2018). Ancak Enes Batur'un yayınladığı bir videoda çocuklara kötü örnek olabilecek görüntüler bulunduğu gerekçesiyle ödül geri alınmıştır (Habertürk, 2017). Tartışmaların olduğu dönemde, Çocukları Taciz ve Sosyal Medyadan Koruma Derneği sosyal medya fenomenleri Kerimcan Durmaz, Enes Batur ve Danla Bilic hakkında çocuklara kötü örnek oldukları gerekçesiyle suç duyurusunda bulundu (Hürriyet, 2018). Sosyal medya hesabı üzerinden eleştirilere cevap veren Danla Bilic ağlamasınlar diye çocukların eline telefon ve tabletleri veren aileleri eleştirirken çocukları iyi yetiştirmenin yolunun başkalarının özgürlüğünü kısıtlayarak olmaması gerektiğini ve internette, televizyonda birçok küfürlü içeri varken kendilerinin linç edildiğini söyledi (CNN Türk, 2018). 
Medya toplumda var olan konuları seçer, ham enformasyonu egemen değerler üzerinden işleyerek topluma geri verir, toplum bu bilgiyi/haberi konuşur ve devreye uzmanlar, aktivistler, yasa yapıcılar girer ve sonuçta egemen söylem yeniden üretilir. Türkiye'deki vakaya baktığımızda benzer süreç kendini gösterir: Fenomenlerle ilgili tartışmalara medyanın dâhil olması spiral döngü içinde konuyu büyütmüş, fenomenler haber ve magazin programlarında tartışılmaya başlanmış, konu çocukları sosyal medyadan korumayı amaçlayan bir dernek tarafından yargıya taşınmış ve sonunda politikacılar tarafından sanal dünyaya yasal müdahale söylemleri gündeme gelmiştir. Resmi Gazete'de yayımlanan "Radyo, Televizyon ve İsteğe Bağlı Yayınların İnternet Ortamından Sunumu Hakkında Yönetmelik" yeni tartışmaları beraberinde getirmiş, YouTube üzerinden yayın yapan içeriklerin de RTÜK tarafından denetlenebileceğini söylemiştir (BBC, 2019).

Bu çalışmada önce ahlak paniği kavramı tarihsel süreçte ele alınmış, bunun kökenlerinin modern toplum kaynaklı olmasından dolayı modernite ve ahlak paniği ilişkisine bakılmış ve son aşamada ise analizine geçilerek fenomenler etrafında oluşan çevrimiçi topluluğa dijital etnografik bir inceleme yapılmıştır. "İçeride" konuşulanlar, bize aslında "dışarıda" konuşulanın ne olduğunu, nasıl olduğunu analiz etmemiz konusunda önemli veriler sağlar. Bu bağlamda içeride oluşan semantik, fenomen ve fenomenin etrafındaki çevrimiçi topluluğun oluşturduğu metinsel dünyadır. Bu metinsel dünyadan ahlaki tartışmalar okunmaya çalışılmıştır.

\section{Ahlaki Panik ve Medyanın Rolü}

1960'ların başında moderniteye olan eleștiriler netleşirken diğer yandan toplumsal alanda modernizmin getirdiği ilerlemeci, düz ve pür yapı bozulurken devletin korumacılığı ve yurttaşlık duygusu, geç modernite döneminde kırılmaya başlamıştır. Birey metropollerde, devlet korumasının çözüldüğü bir yapıda büyük bir boşluk içine düşmüştür. Bu boşluğu, daha sonraki süreçte tekrar dünya sahnesine dönen din, etnisite, cinsiyet temelli kimliksel cemaatler gibi arkaik kökenlerinin geçmişte arandığı bir geleneğin çağrılması doldurmaya başlayacaktır. Modernitenin sorgulanması, sosyal hareketler, ekonomik çöküş, ulus devletlerin ve parlamenter sistemlerin sarsılması, hepsi toplumda alışılmış değerlerde bir değişime neden oldukça paniği de beraberinde getirmiștir. Değișimi en belirgin ve hızlı bir şekilde gençlik kültüründe görmek mümkün olduğundan dolayı, özellikle Avrupa'da sosyologlar 60’lı yıllardaki gençliğin altkültürleriyle ilgilenmiştir. Çünkü sistemde kırılmanın kendisini en net gösterdiği yer gençlik ve altkültürlerdir.

Ahlaki panik çalışmaları, Jock Young'ın (1971) uyuşturucu almanın sosyal analizine ve Stanley Cohen'ın (1972) Mods - Rockers olaylarının kanonik incelemesine kadar uzanmaktadır. 1970’lerde ve 1980’lerdeki gelişmeler, medyanın sapkınlıkların abartılmasında oynadığı role odaklanırken 1990'larda kültürel sosyolojide ve ahlaki düzenlemelerdeki ilerlemeler geleneksel araștırma odağını genişletmiștir. Ahlaki panik kavramına ilginin sürekli olmasına rağmen bu alandaki çalışmalarla ilgili tartışmalar devam etmektedir (Hier, 2011, s.1). Medya ve okuryazar halk kitleleri, ahlaki paniğin söylemini çekici bulsa da kavram sosyologlar arasında tartışmalara yol açmıştır. Ahlaki panik literatürünün dışında çalışan sosyologlar ahlaki panikle ilgili söylemi; sosyal problemler, sapkınlık ve kolektif davranış sosyolojisinde var olan açıklayıcı çerçevelere tam anlamıyla yerleştirmemekteyken diğer yandan ahlaki panik hakkında yazan sosyologlar ise uygun analitik parametreler üzerinde hemfikir değildir. Ahlaki paniğin uygulanmasını karakterize eden huzursuzluk, analistlerin literatürdeki belirli açıklayıcı bileșenleri benimsemelerine veya belirli sosyal eylem biçimlerini eleştirmek için kullanılan değer yüklü bir siyasi nitelik olarak reddetmelerine yol açar. Ahlaki paniğin 
kilit bir sosyolojik kavram olarak faydası, esnek uygulamasında bulunur. Ahlaki panik, ampirik şekilde bağlanmış fakat analitik olarak sosyal sorunların inşası süreçlerinden ayrı bir tür şeklinde özel bir sosyal sorunu temsil eder (Goode ve Ben-Yehuda, 2011, s.20).

Ahlaki panik, ufak tefek toplumsal sapkınlık edimlerine karşı abartılı ve iletişim araçlarınca büyütülen toplumsal bir tepkidir (Mutlu, 2004, s.283-284). Ahlaki panik, algllanan bir sosyal soruna karşı aşırı tepki türünü açıklamayı amaçlayan sosyolojik bir kavramdır. 1960'ların sonlarının çalkantılı siyasal ve entelektüel bağlamı içinde geliştirildiğinde amacı, sosyal bir sorunla ilgili endişe yaratmadaki süreçleri ortaya koymaktı (Rohloff ve Wright, 2010, s.404). Ahlaki panik, inanç sistemlerine dayanan ve ideolojik anlam sistemlerine bağlı olan fikirler hakkında yoğun bir tartışma alanı oluşturur; bize sosyal ve politik olarak neler olduğunu anlatır. Bu nedenle, ahlaki panik zamanlarında, güçlü ve duygusal bir politika anlayışı sergileyen sadece popülist yorumcular değildir; ahlaki panikten çaresiz kalan her insan öfkeden yabancılașmaya kadar değișen duygusal ve somutlaştırılmış tepkilerden etkilenebilmektedir (Lumby ve Funnell, 2011, s.280).

Ahlaki paniğin ana unsurları veya aşamaları şunlardır (Thompson, 1998, s.8): 1. Bir şey veya birisi, değerlere veya ilgi alanlarına tehdit olarak tanımlanır. 2 . Bu tehdit, medya tarafından kolayca tanınabilir bir biçimde tasvir edilmiştir. 3. Hızlı bir kamuoyu kaygısı oluşur. 4. Yetkili makamlardan veya fikir yapıcılardan bir cevap alınır. 5. Panik, toplumsal değişimlere neden olur veya geri çekilir. Bu tür tehditlere verilen yanıt daha büyük bir sosyal düzenleme, kontrol ve geleneksel değerlere geri dönüş talebi olabilir. Ahlaki panik hakkındaki literatürün çoğu, bu gibi durumlarda; kitle iletişim araçları, baskı grupları, politikacılar, kamuoyu, polis ve yargı gibi sosyal düzenlemeye çağrı yapan veya empoze edenlerin nedenlerini açıklamaya çalışmakla ilgilidir.

Toplumlar, her zaman ahlaki panik dönemlerine maruz kalmaktadır. Savaştan sonra Britanya'da en çok tekrarlanan ahlaki panik, sapkın olarak görülen gençlik kültürleriyle ilgilidir. Teddy Boys, Mods-Rockers, The Hells Angels, dazlaklar ve hippiler gibi altkültüler genellikle toplumdaki uyuşturucu, öğrenci olayları, politik gösteriler, holiganizm, vandalizm, suç ve şiddet olayları ile ilişkilendirilmiştir (Cohen, 2014, s.356). Ancak, Teddy Boys ile Mods - Rockers gibi gruplar, sadece belirli olaylar ya da belirli onaylanmayan davranış biçimleri açısından değil, aynı zamanda ayırt edilebilir bir sosyal tanımlanma işlevi de görür. Toplumun üyelerine hangi rollerden kaçınılması ve taklit edilmesi gerektiğini göstermek için bu gruplar halk şeytanları olarak İngiliz toplumunun ne olmamaları gerektiğinin gözle görülür hatırlatmaları şeklinde bir pozisyonda kalmıştır. Bu tür sosyal kimlikler kamu mülkiyetidir ve bu ergen grupları, İngiltere'de gerçekleşen toplumsal değişimi sembolize etmiştir. Bir koşul, kişi veya bir grup; toplumsal değerler ve çıkarlar için bir tehdit olarak tanımlanabilir; kitle iletişim araçları tarafından stilize edilmiş ve basmakalıp bir biçimde sunulabilir. Ahlaki barikatlar editörler, din adamları, politikacılar ve diğer doğru düşünen insanlar tarafından yönetilmektedir. Sosyal akredite uzmanlar teşhis ve çözümlerini söyler; başa çıkma yolları geliştirilir. Bazen panik nesnesi oldukça yeni ya da aniden ilgi odağı olarak ortaya çıkan bir şey olabilirken bazen de kolektif hafızada unutulur (Cohen, 2002, s.1-2).

Toplumlarda dönem dönem yaşanan ahlaki panik, özellikle egemen kültür dışında kalan ırk, din ya da cinsiyet gibi sistem tarafından ötekileștirilmiş gruplar ya da egemen kültüre karşı duran altkültürlere yönelik bir ötekileştirmeyi ve medya üzerinden bir söylem üretimini de beraberinde getirmektedir. $\mathrm{Bu}$ dönemlerde toplum, birçok olumsuzluğu belli gruplara yüklemeye başlar. Öyle ki bu durum bazen histerik hâle gelir ve toplumdaki 
bütün olumsuzlukların neredeyse günah keçisi ilan edilen bu grupların varlığı üzerinden gerçekleştiği algısı oluşur.

Ahlaki paniği anlamak için ahlakın ne olduğu hakkında bir sorun karşımıza çıkmaktadır. Kültürel olarak onaylanmış hedeflere adanmış arayış, tedirgin edici hedeflerden kaçınma, normatif olarak onaylanmış araçlara bağlılık gibi durumlar belirli bir öz kısıtlama, çaba, disiplin, engelleme anlamına gelir. Açıkça çıkarlarına zarar vermese de ahlaki olarak disiplinsiz olanın ya da kötülüğün eğilimlerinin, erdemliliğin huzuru üzerindeki etkisi nedir? Bu noktada erdemli, kendine bir avantajyaratabilir, kendini ahlaki açıdan zayıf olanla kıyaslamalardan kurtarabilir (Cohen, 1965, s.6-7). Weber'e (1978, s.24-25), göre sosyal eylemler dört şekilde ele alınabilir. Birinci eylem olan Zweckrational, diğer insanlardaki davranışlarına ilişkin açıklamalarla belirlenir. Bu beklentiler, aktörün rasyonel olarak izlenen ve hesaplanan sonuçların elde edilmesinde şartlar veya araçlar olarak kullanılır. İkinci eylem Wertrational, başarı beklentilerinden bağımsız olarak; etik, estetik, dinî veya diğer davranış biçimleri uğruna kendi değeri için bilinçli bir inançla belirlenir. Üçüncüsü duygusaldır, oyuncunun kendine özgü etkileri ve duygu durumları tarafından belirlenir. Dördüncüsü gelenekseldir, yerleşik alışkanlıklar tarafından belirlenir. Bu dört yönelimden ilk ikisi Goode ve Ben-Yehuda (2011, s.21) tarafından ahlak değerlendirmesi için ele alınır. Weber'in değerlendirmelerine göre ahlakı ele aldığımızda, ahlaki bir panikte ahlak, verilen bir mutlak değeri ihlal eden öfkenin ifadesidir; diğer deyişle toplumun bir kesiminin kendi içinde iyi olduğunu düşündüğü bir şeyin baltalanmasıdır. Genel olarak ahlaki panik, gerçek bir tehlike ya da potansiyel zararla orantılı olmayan bir yolsuzluk aracısının sözde tehdidi üzerine ahlaki kaygının patlak vermesidir. Tehditler gerçek olabilir; ancak bunlar zararın ciddiyetini, kapsamını, tipikliğini veya kaçınılmazlığını abartmaktadır. Diğer deyişle ampirik olarak değerlendirilen kaygı, nesnel tehdide orantısızdır. Ahlaki panik içerisindeki başlıca aktörler sözde bir tehditle ilgili hikâyeler yayınlayan medya; politikacılar, milletvekilleri, polis dâhil yasa temsilcileri ve muhtemel tehdide karşı lobi yapan sosyal hareket aktivistlerden oluşur. Ahlaki panik; ahlaki bir evrene karşı varsayılan bir tehdit tarafından yaratılan aldatma, öfke ve aynı zamanda saldırgan olarak algılanan insan kategorisiyle, kısacası bir "şey" ile ilgilidir. Bu "şey", Young'ın (2007, s.60) dikkat çektiği gibi gerçek korku nesnesi olmasa da başka bir korkunun yerinden olması ya da gerçek dezavantajın gerçek nesnesinin gerçek tehdidinin yanlış anlaşılması olabilir. Ayrıca en önemli vakalarda panik objeleri; temel değerlere, disiplin stratejisine ve panik yapanların gerekçelerine sadece maddi anlamda değil, aynı zamanda ahlaki ve sembolik olarak doğrudan bir tehdit oluşturur.

Her toplum sapmaya neyin sebep olduğu hakkında bir takım fikirlere sahiptir. Sapkınlığı kimin yaptığı ile ilgili imgeler, davranışla ilgili bilgileri şekillendirir. Sanayileşmiş toplumlarda, bu tür fikirlerin inşa edildiği bilgi gövdesi, kaçınılmaz olarak ikinci elden sağlanır. Yani bu, kitle iletişim araçları tarafından hâli hazırda işlenmiş olan haberi neyin oluşturduğu, haberin nasıl toplanması ve sunulması gerektiği konusunda alternatif tanımlara tabi olduğu anlamına gelir. Bilgi, medyadaki çeşitli ticari ve politik kısıtlamalar ile daha da yapılandırılmıştır. Ahlaki girişimci ise kitle iletişim araçlarının sosyal sorunları tanımlama ve biçimlendirmedeki rolüne dikkat edemez (Cohen, 2002, s.9). İnsanlar haberi okurken enformasyonun nasıl işlendiğini bilemez. Kaldı ki bilinç, her haberin hangi aşamalardan geçtiğini her daim sorgulayacak bir yapıda değildir. Dolayısıyla tüketilen haberin "bilinçli" insanda dahi bir panik hâli yaratması beklenen bir durumdur. Burada sansasyonel haber yapmak için ahlaki değerler sorgulanabilirken diğer yandan egemen söylemin yeniden üretimine hizmet edilmektedir. 
Medya; sosyal problemler yaratabilir, dramatik bir şekilde sunabilir, bunu aniden yapabilir, kamuoyunun öfkesini çok hızlı ve etkili bir şekilde destekleyebilir, sapkınlığın belirli bir kısmı hakkında ahlaki bir panik dediği şeyi düzenleyebilir. Gazete başlıkları sürekli olarak ahlaki kayıtsızlıktan kaynaklanan bazı yeni tehlikeler konusunda uyarmakta ve televizyon programları temayı sansasyonel belgesellerle yansitmaktadır (Young, 1971, s.37). ${ }^{1} \mathrm{Bu}$ anlamda ahlaki panik yeni bir şey değildir. Örneğin önce caz ve sonra rock'n' roll'un gençliği umutsuzluğa ve antisosyal davranışlara yönlendirdiği söylenmiștir. 1950'lerde ise gençlerin kafe-barlarda zaman geçirmesiyle ilgili bir panik varken 1960'lı yılların cinselliğin geleneksel aile değerleri üzerinde yıkıcı bir etkiye sahip olduğuna inanılmış ve feministler aile hayatını baltalamakla suçlanmıştır. Daha sonra 1970'lerde, hukuk ve düzen konusunda genç siyah soyguncuların görüntüsü karşımıza çıkar. Medya, kamuoyu, çıkar grupları ve otoritelerin etkileşimi sonucunda bir sarmal etkisi oluşur (Thompson, 1998, s.1-2). ${ }^{2}$

Bulaşıcı hastalıklar (SARS, kuş gribi), satanizm, tinerci çocuklar, uyuşturucu kullanımı, intiharlar, Batı'da okullara düzenlenen silahlı saldırılar, alışveriş merkezlerine düzenlenen terörist saldırılar, deprem söylentisi, cinsel tacizler, kapkaç olayları, ırkçı saldırılar vb. Türkiye ve dünyada görülen ahlaki panik örnekleridir. Panik, önceleri genellikle aşırı sağ ya da sol gibi koyu ideolojistlerin kendi ideolojilerini koruma için yaratılsa da (Soygüder, 2007, s.108-109), artık panik sanal alana yönelip yön değiștirerek nitelik değiștirmeye başlamıştır. Panik önceleri belli ideolojik gruplarda kendini daha çok gösterirken var olan düzeni korumaya yönelik tutucu ideolojik tez kendini korumakla birliktedijital kültür içinden gelmeyenlerde, diğer deyişle kuşaksal ayrımda daha belirgin görülmeye bașlanmıştır.

Medya; toplum, çıkar grupları, otorite arasında oluşan spiral sarmalda paniği büyüten önemli bir amplifikatör olarak karşımıza çıkmaktadır. Medya bunu egemen söylemi üretmek için de yapabilir ya da haber üretmek için yaparken egemen söylemi üretmiş de olabilir. Her hâlükârda üretilen aslında egemen söylemdir. Özellikle dijital kültür, her kültürde ciddi bir tehlike olarak algılanmaktadır. Ancak dijital medyadan önce de geleneksel medyaya da benzer olarak eleştiriler -her yeni teknolojiye yapıldı̆̆ı gibi- olmuştur.

\section{YouTuberlar ve Çevrimiçi Kültür}

YouTube, üretici-tüketici bölünmesini ortadan kaldıran, pazar ile pazar dışı ve sosyalekonomik faaliyet arasındaki dinamik ilişkilerin bölgesi olan bir platformdur. Televizyon gibi yayın medyasında görünür katılıma erişim, kurumsallaşmış profesyonellik ile sınırlıyken YouTube açık ve belirsiz bir platformdur. Siteye katkıda bulunanlar; televizyon istasyonları, spor şirketleri ve reklam verenler gibi büyük medya üreticilerinden küçük-orta ölçekli işletmelere veya genel yayın sistemlerine, kültürel kurumlara, sanatçlara, aktivistlere, profesyonel olmayan ve amatör medya üreticilerine kadar uzanan bir çeşitliliğe sahiptir (Burgess ve Green, 2009a, s.90-103). YouTube, çevrimiçi izleyiciye televizyonda olmadan ünlü olacağını göstermiştir. İnsanlar yeteneklerini, evcil hayvanlarını veya çocuklarını içeren videolarıyla ulusal ya da uluslararası üne kavuşmaktadır (Strangelove, 2015, s.15). Burgess ve Green (2009b, s.viii), YouTube'un popülerleşmeye başladığı dönemde Batı'nın İngilizce konuşan dünyasındaki hızlı yükselişi, çeşitli içerik yelpazesi ve kamuya açıklığı, yeni medya teknolojileri, yaratıcı endüstriler ve popüler kültür politikaları arasındaki değișen ilişkileri anlamaya yardımcı olduğunu söylemiştir. Ancak bu argüman, bugün neredeyse dünya genelinde geçerli olmaya başlamıştır. Bugün her kültürde belirli bir hayran kitlesi olan, çeşitli 
temalarda (gezi, moda, makyaj, eğitim, bilim vb.) yayın yapan ve belirli bir üne sahip YouTuberlar vardır.

Sosyal medya ünlüleri için kullanılan mikro-ünlülük, geleneksel ünlüye benzese de aynı şey değildir (Senft, 2008, s.25). Sosyal medya, insanların başkalarının tüketmesi için kendilerini halka açık bir kişi olarak gördükleri, takipçilerine hitap etmek için stratejik bir samimiyet kullandıkları ve izleyicilerini hayran (fan) olarak gördükleri mikro şöhreti mümkün kılan bir yapıya sahiptir. Mikro ünlülük, bir hayran kitlesi olan, popülerliğin bu kitlenin yönetimi aracılığıyla sürdürüldüğü ve kişisel sunumun başkaları tarafından tüketilmesi için yapıldığı bir zihniyet ve pratikler bütünlüğüdür (Marwick, 2016). Gençlerin egemen kültürden kimlik yaratmak amacıyla farklı olarak ürettikleri yapılar, kimliklendirme süreçlerinde işlev görmektedir. $\mathrm{Bu}$ nokta karşılıklıdır. Yani sosyal medyada fan kitlesine sahip olan ile takipçi için zemin aynıdır ve üstelik rollerin her an değișme ihtimali de vardır. Çünkü sosyal medyada mikro ünlülük, geleneksel ünlülükten farklı olarak ciddi bir mobilizasyonu, güncellenmeyi, değişimi, demokratik bir yapıyı gerektirmektedir. Kullanıcılar, anlamlandırma süreci içinde metinsel bir dünyada metinsel bir eylem gerçekleştirirler.

Anlam üretmek ve kendi hakikatini organize etmekle yükümlü olan modern bireyler, teknoloji gücünün aşkınlığıyla yeni kimlikleri arzular. Sanal gerçekliğin aşırı uzamsallaştırılması ve kullanıcıların sanal ortamı istedikleri şekilde yeniden biçimlendirme konusundaki göreceli yetenekleri, tarihi doğrusal bir anlatı olarak inkâr etmenin etkinliğini teyit ederken aynı zamanda teknolojinin yazılıma ve kodlara olan güvenini sosyal inșacı argümanını doğrular; bedenlerimiz dâhil tüm dünya bir metindir (Hillis, 2004, s.24). Yazılım servisi ile kullanıcıların semiyotik pratikleri arasındaki bağlantıların çeşitli teorik modelleri ve keşfi, toplumsal gelenekleri içeren değişimler ve teknolojik gelişmeler arasındaki bağı ilgilendiren geniş bir tartışma içine gömülüdür. Sosyal alanlarla bilgisayar teknolojisinin iç içe geçmesi sosyal medya fenomenini derin bir anlama ulaştırır. Sosyal medya, sadece linguistik ve fenomonel gerçekliğin karıștırıldığı inanç gruplarına yol açmaz, aynı zamanda kullanıcıları zaman ve uzam algısı ile diğer insanlar arasında nasıl durduklarını da gösterir (Eisenlauer, 2013, s.xiii- xiv). Dolayısıyla sanal alanın kendine ait bir iletişim kültürü ortaya çıkar.

Kültür; bir sosyal grubun kurumlarda, sosyal ilişkilerde, inanç sistemlerinde, geleneklerde, nesnelerin kullanımlarında yer alan anlamlar, değerler ve fikirleridir; yaşamın maddi ve sosyal organizasyonunun kendini ifade ettiği farklı biçimlerdir ve üyelerine yaşamı anlaşılır kılan haritaları içerir. Bu anlam haritaları, bireyin sosyalleştiği ilişkiler içinde

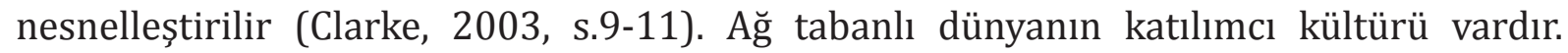
Katılımcı kültür, sanatsal ifade ve sivil katılıma daha az engelin olduğu, yaratmaya ve yaratılanı paylaşmaya desteğin olduğu, deneyimli katılımcıların bilgi aktaranlara bazı informel mentorluk yaptığı bir kültürdür. Bu kültürde ayrıca üyeler katkılarının önemli olduğunu düşünür ve birbirleriyle bir dereceye kadar sosyal ilişki kurduklarını hissedeler. Katılımcı kültürde bireyler, katkıda bulunma konusunda özgürdür. Böyle bir dünyada birçok kişi yüzeysel paylaşım yaparken bazıları da topluluk içinde değerli olan becerilere sahip olacaktır. Ancak topluluğun kendisi yaratıcı ifade ve aktif katılım için teşvik edicidir. Yaratıcı yazılar ve sanat gelecekteki yazı ve sanatı belirlemeye yardımcı oldukları için değil, bu yaratıcı süreç kendi başına değerlidir. Her çocuk, profesyonel olarak yazmasa ve çizmese bile kelime, ses ve imgeler yoluyla kendini ifade etme şansını hak etmektedir. $\mathrm{Bu}$ tecrübelere sahip olmak gençlerin kendileri hakkında düşünme biçimi ve başkaları tarafından yapılmış ișe bakıșlarını değiștirmektedir (Jenkins, Purushotma, Weigel, 
Clinton ve Robinson, 2009, s. xi-6). Ağ kültüründe insanların materyal paylaşımıyla ilgili tek bir sebep sunulamamaktadır. İnsanlar herhangi bir medya metnini yaymaya karar verdiklerinde toplumsal içerikli karar verirler. Çünkü paylaşılan materyalin diğerlerini ilgilendirmesi, paylaşmaya değer olması, belirli insanların ilgisini çekmesi, yayılması için gereken en iyi platformun ne olduğu, belirli bir mesajla birlikte sirküle olması vb. önemlidir (Jenkins, Ford ve Green, 2013, s.13).

YouTube'da kullanıcı topluluğunda, kimsenin yetkili olmamasına rağmen kurallar vardır. Örneğin "hater"lar ${ }^{3}$ tarafından yapılan hareketler ve spam'lar kınanır (Strangelove, 2010, s.118-121). YouTube bir yansıtıcı iletişim modeli sunar. Yansıtıcı iletişim, YouTube'da kişinin kendini özne konusu hâline getirme eğilimini ifade eder, ancak kişi özneden daha fazlasını içerir. Bilinç bir "biliyorum" meselesiyken, iletişim "bildiğimi söylerim" meselesidir, yansıtıcı iletişim ise "bildiğimi bildiğini biliyorum"dur (Strangelove, 2010, s.74). YouTuberlar sitedeki belirli kişilerle hiçbir zaman tanışmayabilir, ancak YouTube'un ayırt edici özellikleri ve sosyal parametrelerini tanıyabilirler. Sosyal etkileşim, halka açık yorumlar yoluyla veya YouTube'un mesaj sistemi aracılığıyla değiştirilen özel mesajlarla kurulabilir (Lange, 2008, s.87-88). Çevrimiçi ilişkilerde benliğin tezahürleri ortaya çıkar. Benlik kendi bağlamında çerçevelenir ve farklı bağlamlarda farklı benlikleri ifade ederiz. Çevrimiçi günlüğü, benliğin çoğul karakterini yansıtır ve deneyimlerimizin çoğul hâllerini nasıl üretebileceğimize dair içgörü sağlar (Strangelove, 2010, s.77). Şöyle düşünebiliriz ki burada bir sanal kamu vardır ve bu kamu değișken ve akışkan olmakla birlikte genel olarak üretilmiş içeriği tüketmiş insanlardan oluşmaktadır. Bu içeriklerde merkezî olan, kanalın sahibi fenomendir. Dolayısıyla temelde bir benlik sunumu vardır. Ahlaki paniğin başladığı nokta da aslında bu benlik sunumunda yatar. Fenomenin kendini nasıl sunduğu tartışma konusudur.

Sanal alanın kendine ait bağlamsallığı içinde hareket eden fenomenlerin anaakım medya tarafından haberleştirilmesi ise tartışmaların merkezini oluşturur. Anaakım medya sanal kültür içinde bilinen bir konuyu alıp yeni bir şey olarak işlemektedir. Medya paniklerinin konusu olan YouTube'un kullanımı, bir bütün olarak YouTube topluluğunun uygulamalarını temsil etmediğine ve gazeteciler tarafından açığa çıkarılan rahatsız edici videolar basına maruz kalmadan önce, nispeten daha az sayıda izlendiğine dikkat çeken Burgess ve Green'in (2009b, s.20-21) tartışmalar hakkındaki tespitleri önemlidir:

\footnotetext{
"YouTube'un iyi veya kötü kullanımları hakkındaki tartışmalar, etik hakkındaki fikirlere dayanıyor. Ancak, YouTube'a katılım etiği, önceden belirlenmiş ahlaki standartların yerine getirilip getirilmediğine dair yargllarda bulunmaya indirgenmemelidir. Daha pragmatik olarak, etik, canlı olarak hareket etme özgürlüğü ve kapasitesi olarak tanımlanabilir - yani, bir kişinin kendi uygulamasının ahlaki sonuçları hakkında düşünmek ve bu etik farkındalığa dayalı eylemleri, belirli bir bağlamla ilişkili olarak formüle etmek olarak tanımlanabilir. YouTube bağlamında etik normlar, YouTube'un sosyal ağında sürekli olarak birlikte oluşturulan, tartışılan ve müzakere edilen uygulama kuralları olarak anlaşılabilir. Yeni medyayı riskin, ahlakın/ahlaksızlığın ve gençliğin bir ifadesi olarak yorumlamanın uzun, tekrarlayan tarihi göz önüne alındığında, YouTube gibi sitelere katılımın, yukarıdan aşağıya kontrol rejimlerinin bir parçası olarak değil, yeni medya okuryazarlığı hakkında daha geniş tartışmaların bir parçası olarak, yansıma, etik farkındalık ve dikkati içerme kapsamını ve koşullarını daha verimli bir şekilde anlamaya çalışabiliriz."
}

YouTube'la ilgili bazı haberler, artık gündelik dile geçen, ancak kültürel araştırmalarda kullanılan ve toplumun ilgisini çeken konulardaki medya ile sosyal gerçeklik arasındaki belirli bir işbirliği nüfusunu tanımlamak için kullanılan bir terim olan ahlaki panik modelini takip eder. Hall ve ekolü, İngiltere'deki soygunun, bu yeni akut soruna 
odaklanmanın kurumsallaşmış ideolojik güç için gerçekte bir krizin ne olduğunu gizlemeye çalıştığını savunarak belirli bir tarihsel konjonktür bağlamında topluma belirli tehditleri temsil eden yeni bir suç olarak inşa edildiğini analiz etmiştir. Böylece polis ve medya soygunculuğu hedef alırken sorun, kamusal hayal gücünde ve gerçekte ahlaki bir panik oluşturarak büyümüștür. Benzer șekilde, YouTube'un anaakım medyada yayınlanmasında, ahlaki bir paniğin özelliklerini sergileyen öyküler, birbirine bağlı toplum kaygısı içermektedir (Burgess ve Green, 2009b, s.18).

\section{Yöntem ve Bulgular}

Sanal dünya ile ilgili araştırma yöntemleri içinde nicel yöntemler, detaylı büyük veri setlerini toplamayı sağlasa da nitel yöntemler, toplumsal sisteme bütüncül bakmasından dolayı zamanla kültürlerin inşa ediliş biçimini özellikle etnografiyi kullanarak incelemek için önemlidir. Klasik kültür antropolojisinde olduğu gibi, daha genel olarak var olan ve hatta daha geniş dünyada giderek önem kazanabilecek olgular hakkında bilgi sahibi olabiliriz (Bainbridge, 2010, s.13-14). YouTube'un katılımcı bir kültür alanı olarak nasıl çalıştığının anlaşılmasına katkıda bulunma isteği, hem özgüllük hem de ölçekle uğraşmayı gerektirir ve bu nedenle sosyal bilimlere olduğu kadar insanlara da epistemolojik ve metodolojik zorluklar sunar. Kültürel çalışmalar, medya çalışmaları ve antropoloji yöntemleri, yerel ve spesifiklerin yakın ve zengin bağlamsal analizinde, bu yakın analizin bağlamla diyaloga girmesi, kültürel teoriye rehberlik etmesi ve geri dönmesi konusunda ustalık kazanmıştır (Burgess ve Green, 2009b, s.7). Dijital dönemin bir antropolojik yaklaşımı olarak netnografi, etnografik araştırma tekniklerini bilgisayar aracılı iletişim yoluyla ortaya çlkan çevrimiçi topluluklara uyarlayan nitel araştırma metodolojisidir (Kozinets, 2002). Diğer deyişle ağ etnografisidir. Pazarlama alanında antropolojinin etnografi yöntemini uygulayan Robert V. Kozinets'in geliştirdiği bu yöntem, aslında tüketicilerin düşüncelerini ölçemeye yönelik olarak kullanılmıştır. Bu sayede markalar, hedef kitlelerin çevrimiçi topluluklardaki söylemlerini inceleyerek marka konumlandırma stratejileri geliștirebilirler. Ancak buradaki hedef kitlenin söylem ve davranışlarının takibi, sosyal dinleme gibi teknik takiplerden farklıdır; burada araştırmacının etnografideki gibi bir antropolog gözüyle bakması gerekmektedir.

Etnografya; sosyoloji, kültürel çalışmalar, tüketici araştırması ve diğer çeşitli sosyal bilim alanlarında kullanılan bir antropolojik yöntemdir. Bu terim grupların kendine özgü anlamlarını, uygulamalarını incelemeyi ifade eder. Etnografyanın bulgularının zengin nitel içeriği, açık uçlu olması ve esnekliği her kültüre, yaş grubuna ve hatta bazı insan dıșı tür gruplarına uygulanmasına izin vermiştir. Ağ tabanlı ortam, tüketicilerin gözlemlenemeyen davranışlarına eşi görülmemiş derecede, eşzamanlı ve etkileşimli olarak yeni bir erişim seviyesini sağlamıștır. Netnografi çevrimiçi tüketici gruplarının sembolizmi, anlamları ve tüketim kalıpları hakkında bilgi sağlar, çevrimiçi forumlarda kamuya açık olan bilgileri kullanır. Araştırmacının üretmediği doğal bir ortamda gözlem gerçekleştiği için incelenen grup açısından dikkat çekmeyen bir şekilde gerçekleşir (Kozinets, 2002). Otuz yıllık araştırmalar, çevrimiçi grupların şahsen toplanan gruplarla aynı temel kuralları takip ettiğini ortaya koymuştur. Örneğin, grup normlarının geliştiği yollar ve grup kimliğinin önemi çevrimiçi ve çevrimdışı gruplarda çok benzerdir. Bununla birlikte, bir dizi araştırma, çevrimiçi topluluğun anonimlik ve erişilebilirlik gibi özelliklerinin farklı bir etkileşim tarzı için bazı benzersiz fırsatlar yarattığını göstermiştir (Kozinets, 2010, s.25). 1990’larda çevrimiçi sosyal etkileşimdeki hızlı değişimlere yanıt olarak geliştirilen yaklaşımın yeniliği, çevrimiçi dünyanın sosyal ve kültürel bir dünya olduğu ve bilimin bu kültürel referans çerçevesini kullanarak çevrimiçi etkileşimleri 
anlaması üzerinedir (Kozinets, 2012, s.39). Çevrimiçini anlamak çevrimdışını anlamayı sağlaması açısından önemlidir.

Çalışmanın amacı, Türkiye'de YouTuberlar hakkında ortaya çıkan ahlaki paniği çevrimiçi alandaki yansımalarıyla birlikte incelemektir. Çalışmada sanal alanın gerçek alandan farklı olmadığını önceleyen bir anlayışla sosyal medya fenomenlerinin çevresinde oluşan çevrimiçi topluluk kültürüne ait tartışmalara bakılmıştır. Ahlaki panik analizlerinde genellikle medya, uzmanlar, yasa ve panik konusu arasında modelin doğrulaması yapılmaya çalışılmaktadır. $\mathrm{Bu}$ çalışma, antropolojik bir tutumla (netnografi) paniğe konu olanın (YouTuberlar) kültürünü (çevrimiçi) inceleyerek konuya yaklaşmaya çalışır ve YouTuberlar ile ilgili ileri sürülen bir ahlaki panikte, paniğe konu olan tarafın kültürüne bakarken paniğin yansımasının niteliği anlayabilmek amacıyla zamansal bağlamda karşılaştırmalı analiz yapar. Bunun için, netnografi yöntemini kullanır. Bu bağlamda çalışmanın hipotezleri ahlaki paniğin çevrimiçi alandaki yansıması üzerinden kurulmuştur: Türkiye'de Youtuberlar ile ilgili bir ahlaki panik vardır. Medyanın bu panikte yükselteç rolü vardır. Medyada panik konuşulmadığında insanlar arasındaki panik de sönümlenmektedir. Çevrimiçi alanın kendine ait kültürel bir yapısı vardır. Çevrimiçi alan, çevrimdışı alanın bir uzantısı olarak ahlaki panik tartışmalarının yansıdığı bir yerdir.

Kozinets'in hedef kitleyi tanımak için pazarlama ve marka alanında geliştirdiği yöntem, bu çalışmada çevrimiçi grubun ahlaki tartışmalara bakışını çözümlemek için Türkiye'deki YouTuberlarla ilgili ahlak tartışmalarına uygulanmıştır. Çevrimiçi topluluk kültürü içinde; hayranlar (fan), sevmeyenler (hater), takipçiler, takip etmeden izleyenler ile birlikte topluluğu oluşturan birçok değişken göz önüne alınarak yapılan bu tartışmalara katılımcı olmayan gözlemle bakılmıștır. Yukarıda bahsedildiği gibi, tartışmalarda birçok YouTuber'ın adı geçse de öne çıkan isimler Enes Batur, Danla Bilic ve Kerimcan Durmaz olmuştur. Örneklem belirlenirken üç sosyal medya fenomeninin Ekim-Kasım 2018 dönemindeki videoları ve karşılaştırma yapmak amacıyla Ekim-Kasım 2019 dönemindeki videoları ele alınmıştır. Bu nedenle bu üç YouTuber'ın bu tarihlerde yayınladıkları videoları dikkate alınmıştır. Seçilen altı videonun araştırma yapıldığı dönemde tarih sabitlendiği andan itibaren toplamda 92290 yorumu vardır. Bu yorumların hepsi okunup temasal olarak değerlendirilmiştir. Ancak çevrimiçi araştırmalarda en büyük sorun verilerin devasalığı ve sürekli güncellenip artmasıdır. Analizde veri miktarını yönetilebilir bir seviyede tutmak için yorumlar sınırlandırılmış ve bu kayıtlar arasından araștırmanın desenine uygun olarak anlamsal ve temasal kodlamaya giren altmış yorum değerlendirilmiştir. Yorumlar, kullanıcılar tarafından yazıldığı şekliyle birebir alınmıştır.

2018 için incelenen videolar şöyledir:

(1) Kanal adı: Enes Batur, Video adı: "AMCAMA PSİKOLOJIKK KIŞKIRTMA (GERÇEK FINAL)", Görüntüleme sayısı: 4.653.325, Yayınlanma tarihi: 26.10.2018, Yorum sayısı: 69694, Erişim adresi: https://www.youtube.com/watch?v=OasTcJu_eug, Erișim tarihi: 18.11.2019.

(2) Kanal Adı: Danla Bilic, "Vize Haftası Makyajı", Görüntüleme sayısı: 1.134.828, Yayınlanma tarihi: 10 Kas 2018, yorum sayısı: 1769, Erişim adresi: https://www.youtube. com/watch?v=T72B5N6FH6E, Erişim tarihi: 18.11.2019.

(3) Kanal Adı: Konumuz Ne TV4, Video adı: "Şey Dermişim \#3 | Aleyna Tilki, Doğum Günüm, Cartier, iPhone XS Max", Görüntüleme sayısı: 1.487.155, Yayınlanma tarihi: 26.10.2018, Yorum sayısı: 658, Erişim adresi: https://www.youtube.com/watch?v=osjMX_qSK0, Erişim tarihi: 18.11.2019. 
2019 için incelenen videolar şöyledir:

(1) Kanal adı: Enes Batur, Video adı: “ENES BATUR KIZI KALDIRDI ?!”, Görüntüleme sayısı: 2.538.120, Yayınlanma tarihi: 25.10.2019, Yorum sayısı: 13986, Erişim adresi: https:// www.youtube.com/watch?v=xZuGQd4U9y8, Erişim tarihi: 18.11.2019.

(2) Kanal adı: Danla Bilic, Video adı: "BABAM YOUTUBE KANALINI KAPATIYORSUN DIYE MESAJ ATTI! / SORULAR SORULAR”, Görüntüleme sayısı: 1.788.278, Yayınlanma tarihi: 08.11.2019, Yorum sayısı: 2805, Erişim adresi: https://www.youtube.com/ watch?v=XCY0wlvga-E, Erişim tarihi: 18.11.2019.

(3) Kanal adı: Kerimcan Durmaz, Video adı: "METRODA TWERK YAPTIM!!! NEW YORK'U BİRBİRİNE KATTIM!", Görüntüleme sayısı: 171.867, Yayınlanma tarihi: 15.11.2019, Yorum sayısı: 1689, Erişim adresi: https://www.youtube.com/ watch?v=ND9rQUP46LQ\&t=1732s, Erişim tarihi: 18.11.2019.

\section{Dışarının Gündemi: Ahlak Tartışmalarının İçeriye Yansıması}

Topluluğun oluşturduğu en önemli konu, sanal alana ait olmayanın ve hatta paylaşım içinde yer alamayanın sanal alanda kullanımıdır. Diğer deyișle dışarının içeriden farklı olmaması söz konusudur. 2018 yılına ait ahlaki tartışmalarının yaşandığı dönemde bunu net olarak görmekteyiz. Ahlak tartışmalarının genellikle iki kutuplu bir eksende gerçekleşmesinden dolayı, yorumcu tipleri fenomeni destekleyenler ve desteklemeyenler ya da hayranlar ve hater'lar şeklinde karşımıza çıkmaktadır. Öncelikle destekleyenlere baktığımızda 2018'deki panik ortamı mesajlara âdeta blok destekler olarak yansımıştır. Fenomenler videonun içeriğinde bu konuyu ele almasa bile hayranları videoya bu konuda yorum yaparak desteklerini iletirken desteklemeyenler de eleştirilerini yazmıştır. Bir kutupsal ortam söz konusudur ve her kutupsal ortamda olduğu gibi ayrıntılar ve ara renkler ortadan kalkmakta, söz konusu olan obje, kişi, grup ya da ideolojiye yönelik bloksal bir destek ya da eleştiri söz konusu olmaktadır. Zaten 2019'a geldiğimizde, yani ahlak tartışmaları sönümlendiğinde, takipçilerin kendi gündemlerine döndükleri görülmektedir. Hayranı olduğu fenomeni bizzat kendi eleştirmeye başlamıştır. Örneğin videonun içeriği, fenomenin benlik sunumu, saç rengi, kıyafet ya da nasıl videolar görmek istediğine dair fenomenin sevenleri yorum yapmaktadır. Bu dönemde her ne kadar kısmen devam etse de hater'lar da azalmaktadır. Ancak genel olarak söylersek hayranların ahlak tartışmaları döneminde baskın bir desteği söz konusudur. Öyle ki yaşının küçüklüğünü özellikle belirtip kendisinin olumsuz etkilenmediğini ya da annesine babasına söylemeyeceğini ya da ne olursa olsun izlemeye devam edeceğini söyleyen ergenlerin olduğu görülmektedir.

Destekleyenler şöyledir:

"Abi biz senenin OLENE DEK YANINDAYIZ." (Enes Batur, 2018)

"Abi senin böyle bir șey yapmayacağını biliyordum" (Enes Batur, 2018)

"Enes abi her neolursa olsun biz senin arkandayız" (Enes Batur, 2018)

"Abi ben biliyordum zaten sen asla böyle bir şey yapamazsın" (Enes Batur, 2018)

"AHHHH DANIELLAAA YİNE Mİ MÜKEMMELSINNN" (Danla Bilic, 2018)

"13 yaşındayım ve sana bayılıyorum seni izlemeden duramıyorum ve beni kötü etkilemiyosun" (Danla Bilic, 2018)

"Abla eskisi gibi ol ya annesine babasına söylicekler izlemesin yha" (Danla Bilic, 2018)

"seni izlemeye ailem kızmıyor" (Danla Bilic, 2018)

"Ya siz efsanesiniz sizden nasıl nefret edip bu denli eleștiriyorlar anlayamıyorum samimiyetlikten ölceksiniz diye korkuyorum her video 2-3 sefer izlenir mi ya ? Bayıllyorum 
size ve çok güldürüyorsunuz beni keşke her gün video yapsanız \#fckhaters" (Konumuz Ne TV, 2018)

“Ayyyyyyyy effsannee.. Gülmekten ağladım ndbdvsnsvs” (Konumuz Ne TV, 2018)

"Seni çok seviyorum bebeiğimm" (Konumuz Ne TV, 2018)

"Kahkaha atarak izledim gerçekten harikasınız" (Konumuz Ne TV, 2018)

"Geberdim gülmekten iyi ki varlar" (Konumuz Ne TV, 2018)

"Tiksiniyorum diye yazan arkadaş ! Madem ooo kadar sevmiyorsun neden umursayıpta yazı yaziyorsun hadi naşşşşşş̧" (Konumuz Ne TV, 2018)

"Oooooffff o kadar komiksiniz ki resmen orda canlı canlı izlemek istedim sizi ve deli gibi haklısınız şu ekşiciler de bi sussun uf yeter" (Konumuz Ne TV, 2018)

"Söylediklerin hakkında sana aşırı katılıyorum sonunda şu "hater" lara cevaplarını vermiş oldun" (Danla Bilic, 2019)

"Uzun zamandır bu kadar gülmemiştim efsanesin devamını bekliyoruz" (Kerimcan Durmaz, 2019)

"Metro kısmına bayıldım youtube senin işin"(Kerimcan Durmaz, 2019)

"Gerçek fenomen sensin senin gibisi yok kimse SEN olamaaaaz HOŞGELDIIIIIIN" (Kerimcan Durmaz, 2019)

"Bu kerimcani özlemişim. Sürekli story at" (Kerimcan Durmaz, 2019)

"Olaysın aşkım (WHATEVER)” (Kerimcan Durmaz, 2019)

"Her zaman Olaysın Ablanstar Baby Olayyyyyy Hayırlı Olsun Kanal Sık Sık Video Bekliyoruz" (Kerimcan Durmaz, 2019)

“Mekanın sahibi geri geldi, bebeleri pistten alalım, alalım" (Kerimcan Durmaz, 2019)

"Mekanin sahibi" (Kerimcan Durmaz, 2019)

\section{Eleştirenler şöyledir:}

"Çakala bak kendini akıllı sanıyo bir de" (Enes Batur, 2018)

"Bilim adamlarının tanınmadığı bir ülkede çapulcular cirit atar..." (Enes Batur, 2018)

"Abla eskisi gibi ol ya annesine babasına söylicekler izlemesin yha" (Danla Bilic, 2018)

"Mezun olmayan izlemesin diyon da seni bu mezun olmayanlar izlemese para kazanamazsin jskdjskjd" (Danla Bilic, 2018)

"Ne ukalasın ya nereden geliyor bu özgüven anlamıyorum" (Danla Bilic, 2018)

"10 kasim bugun 10 kasim siz bugunde saçma sapan makyaj vidyolar çekmeye devam edin seni cok ozledik Atam özlemle anıyoruz." (Danla Bilic)

"Hava atma çabaları. Farkında değilsin görmemiş gibi duruyosun. Bayrak etme kendini" (Kerimcan Durmaz, 2019)

"O alkol bağımlılı̆̆ı değil güzelim paranın vermiş olduğu şımarıklık"(Danla Bilic, 2019)

"Videonun \%98i : anladığğğğın mığğğğg” (Danla Bilic, 2019)

"Gerçekten utanç verici bir insansııınnnn" (Enes Batur, 2019)

\section{Ahlaki Panik ve Medya İlişkisinin Okunması}

Paylaşımın konusunda medyadaki tartışmalar geçmese bile YouTuberları eleştiren medya, fenomenin takipçileri tarafından eleştirilmiştir. Hatta 2019'a gelindiğinde haberlerin espri konusu olarak kullanıldığı görülmektedir.

"Enes kardeşim Bu televizyondaki her haber aynı , ben bir tane gerçek haber görmedim hepsi yalan dolan." (Enes Batur, 2018)

"Ulan şu youtuberler olmasa haberciler"(Enes Batur, 2018)

"Haberciler buda size kapak olsun”(Enes Batur, 2018)

"Hadi bunuda haber yapın"(Enes Batur, 2018)

"Show haber : buruna kalem soktu çocuklara kötü örnek oldu çocuklarınızı bu kadindan uzak tutum kdkdkdodo" (Danla Bilic, 2018) 
"son haberler: you tube çocukları esir aldı :: çocuklar boğulacak ünlü you tuber "danla bilic" burnuna kalem soktu" (Danla Bilic, 2018)

"Söylemezsem olmaz programindan eceyle bircan size giydirmişler !! Kendi yaptıkları çok normalmis gibi !! Danla ve kerimcan şunlara haddini bildirin lutfen konu bulamadilar size sallıyolar !! (Konumuz Ne TV, 2018)

"Show haber: enes batur buçakla dehşet saçtı arkadaşını öldürüyordu" (Enes Batur, 2019)

\section{İçerinin Gündemi: Video İçeriğine Yorum}

Ahlak tartışmalarının sönümlendiği dönemde takipçiler artık fenomenin benlik sunumu, video içeriği, klyafet, makyaj gibi kendi gündemlerine dönmüşlerdir. 2018'den farklı olarak takipçilerin kendisi bizzat fenomeni kendi eleştirmeye başlamıştır. Hatta fenomene değiştiği için sert eleştirilerde bulundukları da görülmektedir.

"ESKİ ENESİ İSTIYORUZ"(Enes Batur, 2019)

"Abi sen çok değiştin" (Enes Batur, 2019)

"Abi ekip nerede batura,mervan,muhammet,valles bunlar nerde"(Enes Batur, 2019)

"Hayatımda izlediğim en kötü Enes Batur videosu 5dk nedir yaa birde 10 saniyelik olaylar bir de kıza çok gıcık oldum"(Enes Batur, 2019)

"Eski arkadaşlarının suyu mu çıktı iyice saçma sapan insanlarla takılmaya başladı"(Enes Batur, 2019)

"Amcan ile beraber McKamey manor korku evine git"(Enes Batur, 2019)

“5:45 te baslayan sakının adı nedır” (Enes Batur, 2019)

"Arkadaşlar irem ayrıldı irem fln yazmayın yani boşuna”(Enes Batur, 2019)

"18:04 gülmekten yarıldım fjfnfj" (Konumuz Ne TV, 2018)

“üç bölümdür Berat muhabbetini bekliyordum ulaaaan" (Konumuz Ne TV, 2018)

"Kahkaha atarak izledim gerçekten harikasınız"(Konumuz Ne TV, 2018)

"Geberdim gülmekten iyi ki varlar" (Konumuz Ne TV, 2018)

"Ders calismayinca ailemin bana yapmak istediği kfndkgnksbf" (Danla Bilic, 2018)

“06:51 çok iyi espri lan valla hahahhah" Kerimcan Durmaz, 2019)

"Uzun zamandır bu kadar gülmemiștim efsanesin devamını bekliyoruz" (Kerimcan Durmaz, 2019)

"Metro kısmına bayıldım youtube senin işin"(Kerimcan Durmaz, 2019)

“Danla sal artık şu tokyo vlogunu Allah rızası için”(Danla Bilic, 2019)

"Ev vloğu çek"(Danla Bilic, 2019)

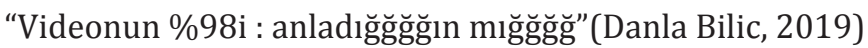

"Tatlıcı hakkında kesin çok soru gelmiştir ama anlatmadı"(Danla Bilic, 2019)

"Alllahını seviyosan saç rengini değiştirirsin”(Danla Bilic, 2019)

"Asla normal degilsin bence geldiğin yeri kaldiramamaya baslamissin herseyi bosvermissin"(Danla Bilic, 2019)

“Şu Kerimcanla aranızda ne oldu Allahisen anlat yeter beeeeg"(Danla Bilic, 2019)

“İzlerken çok sıkıldım. Ne kadar değişmiş"(Danla Bilic, 2019)

\section{Sonuç ve Değerlendirme}

Birçok çalışmada olduğu gibi bu çalışma da göstermiştir ki sanal mekân, zannedildiği gibi 0 ve 1'den oluşan yazılım mühendisliği mimarisi değildir. Sanal alan, gerçek alandan beslenmektedir. YouTube, özellikle sosyal medya fenomenleri etrafinda oluşan topluluk kültürüne sahip bir sosyal alandır. Buradaki sosyallikte, içerinin aslında dışarıdan farkı yoktur. Dıșarıdaki sosyal alan normları nasıl ișliyorsa sanal alanda yine benzer normsal yapıyı görmekteyiz. Fenomenler, zannedildiği gibi "özgürleşmiş", "bağımsız" bir alanda hareket etmezler. Buradaki yeni dilin sınırlarının eski dilden/yapıdan daha belirsiz 
olması, bu alanların gerçek dünyadaki sosyal anlam ve bağlamlardan uzak olduğunu göstermez, hatta kendi anlamsal dünyasını kurabilmesi için bizzat bunlara ihtiyacı vardır. Farklı olan, uzamsal yapılardır. Dolayısıyla yeni metin-mekânsal alanlar gerçek dünyadan kopmadan, ancak onun fiziksel kurallarının getirmiş olduğu normlardan muaf bir şekilde kendi semantiğini kurmaktadır. Buradaki fenomenler ise gerçek dünyadan farklı olarak metinsel bir dünya içinde metinsel eylemlerde bulunurlar. Bu metinsellik ise dışarıdan bağımsız olmayan tekno-sosyal bir alanı karşımıza çıkarır.

Çevrimiçi alan, kamusal ve özelin sınırlarının bulanıklaşması ya da küresel ve yerel olanın belirsizleşmesi gibi daha önce var olan yapılardan çok farklı bir semantiği karşımıza çıkarmaktadır. Teknolojik gelişmelerin getirdiği yeni bağlamsal yapılar kendine ait anlamsal yapıları da berberinde getirmesinden dolayı eski dil ile yeni olanı çözümlemek konuyu çıkılmaz hâle getirebilmektedir. Bu nedenle çalışmanın bize gösterdiği en önemli noktalardan biri, yeni dili yeni bağlamı içinde okumaktır. Bunun için teknolojinin sunduğu sanal mimariden çevrimiçi kültüre kadar birçok konu birbiriyle bağlantılı olarak yeni bir dünyayı yaratır. Bu dünya, her ne kadar fiziksel düzeyde algıladı̆̆ımız dünyadan önemli bir zemin kırılmasıyla farklılaşmış olsa da bu dünya içindeki öznelerin fiziksel dünyadan getirdiği sosyolojik anlam kodları vardır. Dolayısıyla değersel yapıların olumlu ya da olumsuz tartışmaları buradan türer. Tekno-sosyal bir yapıya gömülü olan çevrimiçi alan; kimliğin, benliğin, bedenlerin akışkan olduğu lingustik ve fenomenolojik metinsel dünya olarak karşımıza çıkmıştır.

Çalışma, araştırmanın hipotezlerini doğrulamıştır. Türkiye'de YouTuberlar ile ilgili ahlaki paniğin varlığı sosyal medyadaki tartışmalar üzerinden görülmüștür. Bu paniğin anaakım medya tarafından büyütüldügüune dair ifadeler, tartışmalar içinde en çok dile getirilen konulardan biri olmuştur. Çevrimdışı alanın çevrimiçi alanı etkilemesi sorunsalı, tartışmaların merkezini oluşturmaktadır. Medya panik hakkında konuşmadığında insanlar da paniği konuşmamaktadır. Çevrimiçi alanın kendine ait kültürel bir yapısı ve dili vardır. Fenomenler bu kültür içinde kendilerini inşa ederler.

Ahlaki panik tartışmalarının incelendiği bu çalışmada, YouTube mecrasını kullananların YouTube fenomenlerini destekleyerek ya da eleştirerek dönemin tartışmalarına dâhil olması söz konusudur. Genel olarak burada fenomenler baskın bir şekilde destekleyici yorumlar almıştır. Üstelik fenomenlerin paylaşımlarında medyada çıkan haberlere dair herhangi bir içerik olmasa da yine kullanıcıların video altında büyük oranda bu yönde yorum yaptıkları görülmektedir. Ne zaman ki tartışmalar sönümlenmiştir, o zaman takipçiler kendi gündemlerine geri dönmüştür. Takipçilerin kendi gündemleri genellikle paylaşımın içeriği ya da fenomenin benlik sunumuna yönelik olmaktadır.

2018 tartışmalarının ana konusunun üç sosyal medya fenomeninin yorumlarında ahlaki paniğin yarattığı tartışmalar olduğu görülmektedir. Ahlaki panik tartışmalarında en çok eleştiri alan konu medya olmuştur. Çalışmanın kuramsal bölümünde belirtildiği gibi medya toplumdaki var olan konulardan birini seçmekte, onu işleyip kamuya aktarmakta, dolayısıyla toplumda var olan konu, medya ile abartılarak büyümekte ve spiral sarmal gittikçe genişlemektedir. Bu nokta, fenomenlerin destekleyicileri tarafından okunabilmiștir. Yani medyayı eleștirenlerin hepsi medyanın konuları abarttığını, gündem yaratmaya çalıștığını, olmayan şeyler aktardığını, çarpıtma yaptığını vb. ifade etmektedir. Dolayısıyla YouTuberları izlemekten vazgeçmeyeceklerini de dile getirmektedirler. Diğer yandan ahlaki değerler açısından konulara yaklaşanların, fenomenlerin çocuklara 
kötü örnek oldukları, "boş" ya da "saçma" paylaşımlar yaptıkları üzerinden eleştiride bulundukları görülmektedir.

2019’a gelindiğinde ise durum bir hayli değișmiștir; değișmeyen șey, destekçilerin medyaya olan tavrıdır. Medyanın fenomenlerle "uğraşması", destekçiler arasında espri konusu olarak kullanılmaya devam etmektedir. Diğer yandan fenomenler arasında 2018'den farklı olarak gündemin değiștiği görülmektedir. 2018'de fenomenler ne paylaşırsa paylaşsın, grup içindeki tartışmalar medyadaki ahlaki panik üzerine olmaktayken 2019'daki tartışmalar, fenomenin paylaşımına ya da benlik sunumuna yönelmiştir. Destekleyenler, ahlak tartışmalarının olmadığı bu dönemde, destek mesajı yerine fenomende görmek istediklerini yazmakta ve hatta onu bir takipçisi olarak -video içeriğini, hareketlerini, saçını, kıyafetini- eleştirmektedir. Örneğin Enes Batur ve Danla Bilic'in videoları takipçileri tarafından beğenilmemiş, hatta fenomenin değiştiği söylenmiș, eski hâline dönmeleri istenmiştir. Kerimcan Durmaz ise uzun süredir YouTube'da olmaması ve kanalı yeni açmış olmasından dolayı diğer fenomenlerden farklı olarak 2019 paylaşımında önemli bir destek görmüştür.

Çevrimiçi kültürde dikkat çeken konu, kullanılan dildir. Bu dil, bize çevrimiçi kültürün anlamsal yapılarını bilmeden konulara vakıf olmayacağımızı göstermektedir. Fenomenin destekçisi olsun ya da olmasın sadece fenomen etrafında oluşan çevrimiçi kültürü bilen insanların anlayacağı bir steganografi söz konusu olabilmektedir. Dolayısıyla altkültürün oluşturduğu bir jargon vardır. Yorumlara baktığımızda bunlar fenomenlerin sıklıkla kullandığı ifadeler olabildiği gibi, fenomenlerin taklidi ya da gençlik jargonunda popüler olmuş bir ifade de olabilmektedir.

Son aşamada, YouTuberlar arasında bir değerlendirme yaparsak; tartışmaların 2018'de Enes Batur ile başlamış olmasından dolayı en çok desteğin Enes Batur'a olduğu görülmektedir. Ancak Enes Batur 2019'da tam tersi bir durumla karşılaşmıştır. Ahlak tartışmalarının olmadığı bu dönemde, bizzat kendi takipçileri tarafından eleştirilmiş ve eski hâline dönmesi istenmiştir. Danla Bilic de Enes Batur gibi 2018'de takipçileri tarafından destek görmüş ve 2019'da takipçiler tarafından değiştiği söylenip eleştirilmiştir. 2019'da ise uzun zamandır YouTube'da olmaması ve kanalı yeni açmış olmasından dolayı diğer iki fenomene göre Kerimcan Durmaz’a olumlu yorumlar yapılmıştır.

Genel olarak videolardaki eleştiriler, medyada ahlak ve değer tartışmalarının olduğu dönemlerin "huzursuz ve sağlıksız" yansımasını içeriden, yani çevrimiçi kültürden net olarak görülmesini sağlamıştır. Çünkü kutuplaşmış dönemler insanların sorgulamaksızın eleștirinin hedefinde olan kişileri, grupları ya da ideolojileri savunmasına neden olmaktadır. Oysa bu kutuplaşmanın olmadığı dönemlerde daha önce savunanların bizzat kendileri savundukları konuyu eleştirdikleri görülmektedir. Bu çalışmada 2018'de medyada tartışmaların olduğu dönemde fenomenler önemli ölçüde takipçileri tarafından korunmuş, desteklenmiş, anaakım medya eleştirilmişken 2019'da tartışmaların olmadığı dönemde takipçilerin bizzat kendileri fenomenlerin davranışını eleştirmeye başlamıştır. Aslında bu örneklem, her sosyal ortamın dıșarıdan müdahale edilmediği zaman kendi içinde daha sağlıklı bir sosyal norma sahip olduğunu göstermiştir.

Medya toplumda var olan konulardan birini seçmekte, eğer bu seçtiği konu toplumun belleğinde olan bir korkuysa konu daha çekici hâle gelmekte, zaten hâlihazırda toplumun bilgisinde olan enformasyon işlenip haber olarak topluma yeni bir şeymiş gibi geri verilmekte, toplum daha çok korkmakta, devreye uzmanlar ve nihayetinde yasa yapıcılar girmekte, sarmal genişleyerek bu şekilde büyümektedir. Benzer durumu YouTuberlar 
konusunda bu çalışmada görmek mümkün olmuştur. Sosyal medya fenomenlerinin nasıl içerikler sundukları, sosyal medyayı kullananlar tarafindan zaten bilinen olağan bir durumdur. Ancak konu anaakım medya tarafından ele alınmaya başlandığı andan itibaren sanki yeni bir konuymuş gibi algılanmaktadır. Fenomenlerin paylaşımlarının altına yazılan yorumlar, toplumun bakış açısını göstermektedir. Medya buradaki tepkileri seçmekte, topluma genelleştirmekte ve var olan değerler üzerinden işleyip egemen söylemi yeniden üretmektedir.

Yeni kuşakların çevrimiçi sosyallikleri, ebeveynlerinden farklıdır. YouTube dijital kültürde yetişen nesil için resmi olmayan öğrenme ortamıdır. Yeni dijital iletişim medyası gelecek nesillerin ağa bağlı yurttaşlar ve kendi kendini gerçekleştiren bireyler olarak tam olarak katılabilmeleri için ustalaşmaları gereken becerileri, bilgi kümelerini ve araçları yeniden gözden geçirmeye davet etmektedir. Ancak bazı ebeveynler ve eğitimciler YouTube'u anlamsızlık olarak görse de aslında çocuklar, heterojen ve ağa bağlı kamu arasında kendini gerçekleştirme ve görünür kişiliği elde etmek için yeni teknik araçları kullanma becerisine sahip olmaları gerektiği konusunda bir farkındalık sergilemektedir. Çevrimiçi bir varlığa sahip olmak ve medya aracılı̆̆ıyla paylaşmak, sosyal olarak bağlı bir genç olmanın kilit unsurlarıdır (Lange, 2014, s.9-11).

YouTube'u okumaktaki kilit nokta, zeitgeist'ı okumaktan geçer. Her neslin içinde büyüdüğü zamanın ruhu, çocuklara ve gençlere hayata katılabilmek için sosyalleştikleri bir dil sunmaktadır. Çalışmada bu, net olarak görülen konulardan biridir. Yorumlarda özelikle birçok ergenin ya da gencin fenomenden kötü etkilenmediğini, fenomeni çok sevdiğini, izlemeye devam edeceğini söylemesi bize yeni kuşağın sosyalleșme dilinin artık bu alan üzerinden gideceğini göstermektedir. Bu nedenle bu yeni dilin okunup anlaşılması önemlidir.

\section{Notlar}

1 Cohen (2002, s. 23-26), ahlaki paniği incelediği çalışmasında analiz ettiği Mods-Rockers olaylarının medya envanterini üç başlık altında inceler: Abartı ve bozulma, tahmin, simgeleme. Medyanın rolü reaksiyonun sonraki aşamalarının belirlenmesinde önemlidir. Clacton'daki ilk olayları takip eden Pazartesi sabahı, ulusal gazetelerin konuyla ilgili manşetleri terör ve vahşet kelimeleri ile kendi kendini tanımlayıcı niteliktedir: Day of Terror by Scooter Groups (Daily Telegraph), Youngsters Beat Up Town - 97 Leather Jacket Arrests (Daily Express), Wild Ones Invade Seaside - 97 Arrests (Daily Mirror).

2 Cohen (2002, s. xix); çizgi roman, çizgi film, popüler tiyatro, sinema, rock müziği, video meraklıları, bilgisayar oyunları, internet pornosu gibi popüler medya ve kültürel formlara maruz kalmanın zararlı etkileri olduğu iddia edilen ahlaki bir panik tarihinin olduğunu söyler. Muhafazakârlara göre medya suçu büyülemekte, kamu güvencesizliğini önemsizleştirmekte ve ahlaki otoriteye zarar vermektedir. Liberallere göre ise medya suç risklerini abartmakta, haksız ve otoriter bir suç kontrol politikasını doğrulamak için ahlaki panik yaratmaktadır.

3 YouTube'daki kişiler tarafından kullanılan "hater", "yerel” bir terimdir. Bir "hater" genellikle, bir videoda gereksiz yere sert eleştiriler bırakan, çoğu zaman homofobi, ırkçılık, cinsiyetçilik ve şiddete ya da ölüme ilişkin kalıplaşmış ifadeler kullanan bir kişi olarak tanımlanır (Lange, 2008, s.94).

4 İncelenen YouTuberların tanındıkları adlarıyla aynı olan kanalları vardır ancak Kerimcan Durmaz'ın videoları 2018'de kendine ait bir kanalda yayınlanmamış, farklı fenomenlerle birlikte ortak çalışmalar yayınlanmıştır. Bu nedenle Kerimcan Durmaz'a ait 2018 yılı videosu "Konumuz Ne TV" kanalında Danla Bilic ile birlikte yaptığı programdan alınmıştır ve bu kanaldan alınan videoda Danla Bilic ile sohbet etmektedir. 2019 videosu ise kendi adına açtığı kanalda yayınlanmıştır. 


\section{Kaynakça}

Bainbridge, W. S. (2010). New World View. William Sims Bainbridge (Ed.). Online Worlds: Convergence of the Real and the Virtual içinde (s.7-19). London: Springer-Verlag.

BBC (2019, 2 Ağustos). Netflix: RTÜK'ün internet yönetmeliği ne getiriyor, kurul üyeleri ne diyor?. Erişim adresi (19 Kasım 2019): https://www.bbc.com/turkce/haberlerturkiye-49193378

Burgess, J. ve Green, J. (2009a). The Entrepreneurial Vlogger: Participatory Culture Beyond the Professional Amateur Divide. P. Snickars ve P. Vondereau (Ed.). The YouTube Reader içinde (89-107). Stockholm: National Library of Sweden.

Burgess, J. ve Green, J. (2009b). YouTube Online Video and Participatory Culture. Cambridge: Polity Press.

Clarke, J., Hall, S., Jefferson, T. ve Roberts, B. (2003). Subcultures, Cultures and Class: A theoretical overview. Stuart Hall ve Tony Jefferson (Ed.). Resistance Through Rituals: Youth subcultures in post-war Britain içinde (s.9-74). London: Routledge.

CNN Türk (2018, 8 Kasım). Danla Bilic: Hedef gösteriliyoruz, linç etmek istiyorlar. Erişim adresi (9 Kasım 2019): https://www.cnnturk.com/magazin/danla-bilic-hedefgosteriliyoruz-linc-etmek-istiyorlar

Cohen, A. K. (1965). The Sociology of the Deviant Act: Anomie Theory and Beyond. American Sociological Review, 30(1), 5-14.

Cohen, P. (1972). Sub-Cultural Conflict and Working Class Community. Working Papers in Cultural Studies, No. 2, 5-52.

Cohen, S. (2002). Folk Devils and Moral Panics: The Creation of the Mods and Rockers. London: Routledge.

Cohen, S. (2014). "Deviance and Moral Panics". Tammy L. Anderson (Ed.). Understanding Deviance: Connecting Classical and Contemporary Perspectives içinde (s.356-362). New York: Routledge.

Drotner, K. (1999). Dangerous Media? Panic Discourses and Dilemmas of Modernity. Paedagogica Historica: International Journal of the History of Education, 35(3), 593619.

Eisenlauer, V. (2013). A Critical Hypertext Analysis of Social Media: The True Colours of Facebook. London: Bloomsburry Publishing.

Goode, E. ve Ben-Yehuda, N. (2011). Grounding And Defending The Sociology Of Moral Panic. Sean P. Hier (Ed.). Moral Panic and the Politics of Anxiety içinde (s.20-36). London: Routledge.

Habertürk (2017, 30 Aralık). Altın Kelebek Ödülü geri alınan Enes Batur açıklama yaptı. Erişim adresi (19 Kasım 2019): https://www.haberturk.com/enes-batur-un-altinkelebek-odulu-neden-geri-alindi-enes-batur-dan-aciklama-1776381

Hall, S., Critcher, C., Jefferson, T., Clarke, J. ve Roberts, B. (1978). Policing the Crisis Mugging, the State, and Law and Order. London: MacMillan.

Hebdige, D. (1979). Subculture: The Meaning of Style. London: Routledge.

Hier, S. P. (2011). Introduction: Bringing moral panic studies into focus. Sean P. Hier (Ed.). Moral Panic and the Politics of Anxiety içinde (s.1-16). London: Routledge. 
Hürriyet (2018, 7 Kasım). Enes Batur, Kerimcan ve Danla Bilic'e suç duyurusu. Erişim adresi (9 Kasım 2019): http://www.hurriyet.com.tr/kelebek/magazin/enesbatur-kerimcan-ve-danla-bilice-dava-soku-41011804

İnternet Haber (2018, 21 Ekim). Enes Batur son videosunda amcasına küfür etti kriz çıktı!. Erişim adresi (9 Kasım 2019): https://www.internethaber.com/enes-baturson-videosunda-amcasina-kufur-etti-kriz-cikti-1912631h.htm

Jenkins, H., Ford, S. ve Green, J. (2013). Spreadable Media: Creating Value and Meaning in a Networked Culture. New York: New York University Press.

Jenkins H., Purushotma, R., Weigel, M., Clinton, K. ve Robinson, A. J. (2009). Confronting the Challenges of Participatory Culture: Media Education for the 21st Century. Cambridge: MIT Press.

Kozinets, R. V. (2002). The Field Behind the Screen: Using Netnography for Marketing Research in Online Communities. Journal of Marketing Research, 39, 61-72.

Kozinets, R. V. (2010). Netnography: Doing Ethnographic Research Online. London: Sage.

Kozinets, R. V. (2012). Marketing Netnography: Prom/ot(ulgat)ing a New Research Method. Methodological Innovations Online, 7(1) 37-45.

Lange, P. G. (2008). (Mis)Conceptions about YouTube. Geert Lovink ve Sabine Niederer (Ed.). Video Vortex Reader: Responses to YouTube içinde (s.87-100). Amsterdam: Institute of Network Cultures.

Lange, P. G. (2014). Kids on YouTube: Technical Identities and Digital Literacies. Walnut Creek, CA: Left Coast Press.

Lumby, C. ve Funnell, N. (2011). Between heat and light: The opportunity in moral panics. Crime Media Culture, 7(3), 277-291.

Marwick, A. (2016). You May Know Me From YouTube: (Micro)-Celebrity in Social Media. Marshall, P.D. ve Redmond, S. (Ed). A Companion to Celebrity içinde (s.333-350). Chichester: John Wiley \& Sons.

Mutlu, E. (2004). İletişim Sözlüğü. Ankara: Bilim ve Sanat Yayınları.

Rohloff, A. ve Wright, S. (2010). Moral Panic and Social Theory Beyond the Heuristic. Current Sociology, 58(3): 403-419.

Senft, T. (2008). Camgirls: Celebrity and Community in the Age of Social Networks. New York: Peter Lang.

Soygüder, Ş. (2007). Moral Panic (Törel Ürkü) Kavramı ile Medyada Yer Alan Örnek Haberlerin Değerlendirilmesi. Yeni Düşünceler. 2, 93-110.

Strangelove, M. (2010). Watching YouTube: Extraordinary Videos by Ordinary People. Toronto: University of Toronto Press.

Strangelove, M. (2015). Post-TV: Piracy, Cord-Cutting, and the Future of Television. Toronto: University Of Toronto Press.

Thompson, K. (1998). Moral Panics. London: Routledge.

Weber, M. (1978). Economy and Society: An Outline of Interpretive Sociology. California: University of California Press. 
Young, J. (1971). The role of the police as amplifiers of deviancy, negotiators of reality and translators of fantasy. Stanley Cohen (Ed.). Images of Deviance içinde (s.27-61). Harmondsworth: Penguin.

Young, J. (2007). Slipping Away - Moral Panics Each Side of 'the Golden Age'. D. Downes, P. Rock, C. Chinkin, ve C. Gearty (Ed.). Crime, Social Control and Human Rights: From Moral Panics to States of Denial, Essays in Honor of Stanley Cohen içinde (s.53-65). Cullompton, UK: Willan Publishing. 


\title{
YouTubers and Changing Moral Panic Phenomenon In Turkey with Netnographic Analysis
}

\author{
Işı Tombul (Ph.D.)
}

\section{Extended Abstract}

While the boundaries between technology and cultures have become uncertain, likewise, there has been an uncertainty in human and individual relations. Technology has brought high speed to culture, and everything has started to change rapidly from knowledge to tradition. This rapidity in culture can sometimes be dizzy with a much-spoken expression for technology, because it is sometimes difficult for people to follow the change. As such, changes are even more shocking for older generations. Technology-savvy humans have flexible, variable boundaries. Especially with the emergence of web 2.0 technologies, the diversification and spread of social media services has entered into our lives since the second half of the 2000s.

YouTubers have their fan base. YouTubers produce content on social media. There is a mass of fans gathered around this content production. Fans and haters also form the online community around the content and content producer. There is an interactive communication between the online community and the shared content. The community can make some requests from the content producer, criticize the content producer, and thus provide clues showing how they perceive it with comments they make. In a sense, the culture of this online community provides us with ethnographic data. Since social media includes both public and private spheres, these interpretations appear as a case study in order to see the significant changes in culture. Recent times has seen very controversial content production by YouTubers in general, and these debates also manifest themselves in the form of YouTubers in Turkey. This debate has always taken place since the emergence of social media, but with the inclusion of this media, to a certain extent a wide-scale moral panic occurred in October 2018, the time when Turkish YouTubers were widely discussed publicly. The aim of this study was to determine the emerging moral panic as seen in the eyes of the public with the rise of the social media as it has become widespread in use. As the debates that initially took place in the social media spilled out on the mainstream media, these debates were discussed in magazine programmes. Later on, a civil association took the case to the court with the aim of protecting children from the harmful effects of the social media, which has fuelled the fears and rumours that politicians are taking legal steps to interfere into the cyber world. Therefore, in this study, first of all, the concept of moral panic has been dealt within its historical process. Also, the relationship with modern society and moral panic have been examined, and YouTubers were discussed, and digital ethnographic analysis has been carried out on the online community formed around the social media influencers.

This study, which discussed the moral panic, examined how the moral value debates are reflected in social media users and group culture. Those following a YouTube channel may be involved in the debates of the period by supporting or criticizing YouTube influencers. In general, influencers have received supportive messages, as seen in the comments that they make under the videos. When the debates settled, then the followers returned to their agendas, and they directed their criticism, this time, towards the influencers that they are fan of. The central argument of this study is that the media creates moral panic. 
It was seen that the users could read the moral panic created by the media, and in many messages of 2018, the attitude of the media was criticized. In 2019, people started to talk about topics that were more appropriate to the group culture around the influencer.

The key to reading YouTube is through reading zeitgeist. The spirit of the time that each generation grew up in offers children and teenagers a language by which they socialize to survive. This is one of the issues clearly seen in this study. The fact that we can see from the comments that a lot of teenagers and young people say that they are not adversely affected from the influencers; and that they like them, and they will continue to watch them reveal that the language for socialisation for the new generation will thrive on in this channel. Therefore, it is essential to read and understand this new language.

Keywords: Moral Panic, YouTuber, Micro-Celebrity, Online Culture, Netnography. 